\title{
Diálogo intercultural e respeito: interpretações do vt publicitário birdman (coca-cola) ${ }^{1}$ \\ Raimundo Martins ${ }^{2}$ \\ Pablo Petit Passos Sérvio ${ }^{3}$
}

\begin{abstract}
Resumo
A partir do VT publicitário Birdman, este artigo apresenta resultados parciais de uma pesquisa que discute conjunções e disjunções na celebração de diálogos interculturais. Estes processos são percebidos como promotores de aprendizagem. O texto analisa discursos que advogam em favor de uma postura de respeito e distância em relação à alteridade. Fundamentado nos princípios da educação da cultura visual, este trabalho interpreta informações coletadas através de entrevistas individuais e focais realizadas com alunos do Curso de Licenciatura em Artes Visuais da Faculdade de Artes Visuais da UFG discutindo a pertinência do uso de imagens publicitárias nas práticas educativas.
\end{abstract}

Palavras-chave: Diferença cultural, Educação da Cultura Visual, Imagem publicitária.

\begin{abstract}
Based on the video tape Birdman, this article presents partial results of a research that discusses conjunctions and disjunctions in the celebration of intercultural dialogues. These processes are perceived as promoting learning. This paper analyzes discourses that advocate in favor of an attitude of respect and distance in relation to 'otherness'. Guided by the principles of visual culture education, this work interprets information collected through interviews with students of the Visual Arts Teacher Training Course of the School of Visual Arts/UFG discussing the relevance of using advertising images in educational practices.
\end{abstract}

Key-words: Cultural Difference, Visual Culture Education, Advertising Image.

Birdman $^{4}$ é apenas um entre as dezenas de VTs publicitários que a empresa multinacional Coca-Coca divulga anualmente. De forma sucinta, seu enredo apresenta um jovem que, caminhando a esmo, segue oferecendo seu refrigerante a várias pessoas (mexicanos, irlandeses, indianos, góticos, punks, hip-hoppers) e até mesmo a animais (um passarinho) e objetos (um peixe empalhado). Após partilhar seu refrigerante com cada um deles, o jovem absorve características que se somam, se acrescentam. Quando, enfim, o refrigerante acaba, ele está totalmente transformado e irreconhecível. Ao final, surge, então, a frase que conclui a narrativa: "Viva as diferenças!".

${ }^{1}$ Este artigo é parte de investigação em desenvolvimento, inserida na Linha de Pesquisa "Culturas da imagem e processos de mediação" do Programa de Pós-Graduação em Cultura Visual, Mestrado, Faculdade de Artes Visuais, Universidade Federal de Goiás.

2 Doutor em Educação/Artes pela Southern Illinois University (EUA), pós-doutor pela Universidade de Londres (Inglaterra) e pela Universidade de Barcelona (Espanha) onde também foi professor visitante. É Professor Titular e Diretor da Faculdade de Artes Visuais, docente do Programa de Pós-Graduação em Cultura Visual da Universidade Federal de Goiás.

${ }^{3}$ Bolsista Capes no Programa de Pós-Graduação em Cultura Visual-Mestrado da Faculdade de Artes Visuais da Universidade Federal de Goiás. Especialista em Teoria da Comunicação da Imagem pela Universidade Federal do Ceará e graduado em Comunicação Social (Publicidade e Propaganda) pelo Centro de Ensino Unificado de Teresina, Piauí.

4 Birdman é um VT idealizado por uma agência argentina, filmado em Johanesburgo, na África do Sul, por uma produtora de imagens britânica e com trilha sonora produzida no Rio de J aneiro. Traz na sua estrutura de criação e produção a pluralidade da globalização que marca seu enredo. (COCACOLABRASIL.COM.BR, 2009) 
A narrativa visual é construída com imagens surreais que intrigam e provocam, especialmente, pelo modo como insinuam um engajamento na discussão sobre a importância da diferença cultural, tema que é um dos desafios políticos e teóricos marcantes dos tempos que estamos vivendo. Para muitas pessoas, as discussões sobre a "diferença" ganham eco e amplificam-se impulsionadas por transformações profundas e complexas que aconteceram ao longo da chamada alta modernidade. Relacionam-se a esse momento, por exemplo, a urbanização e a perda dos sentidos tradicionais de coletividade até os fluxos tecnológicos, financeiros, midiáticos, ideológicos e étnicos resultantes tanto do desenvolvimento pós-guerra fria quanto do fenômeno da globalização e, conseqüentemente, da fragilização dos Estados-nação e os deslocamentos diaspóricos pós-coloniais. Tais transformações promoveram um mundo onde o "Outro" tornou-se onipresente, menos distante e abstrato, embora continue sendo pouco compreensível ou tolerável. Um mundo fluido em que tradições necessitam ser constantemente reinventadas, ou seja, um mundo onde é cada vez mais difícil ter certezas (HALL, 2006; APPADURAI, 1996; FEATHERSTONE, 1997).

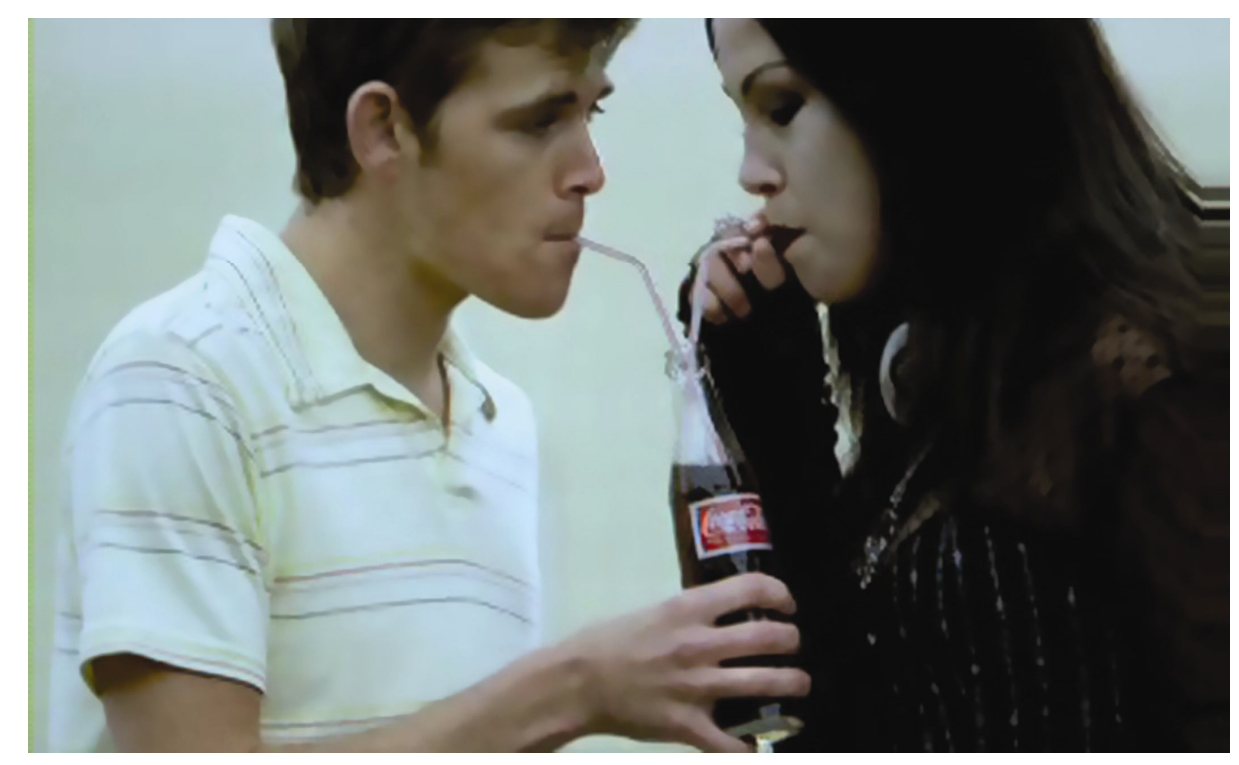

Figura. 01 - Frame do VT Birdman (7o segundo) 


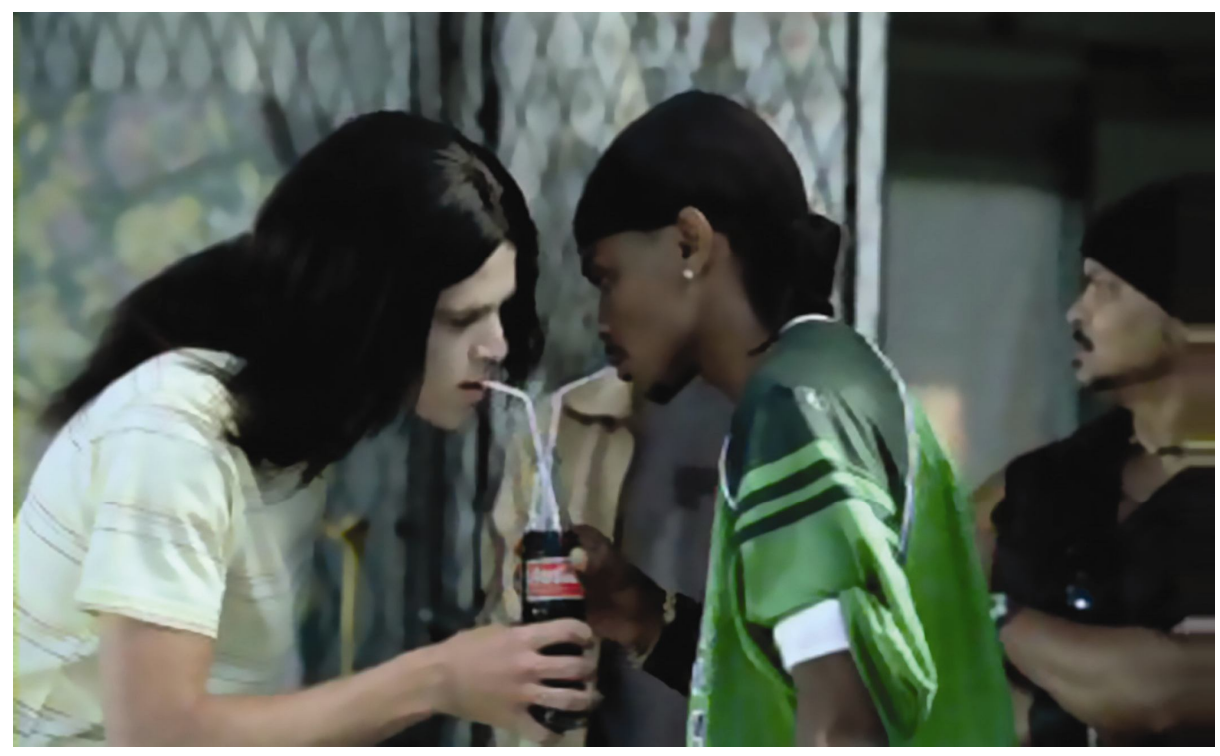

Figura. 02 - Frame do VT Birdman (17ㅇ segundo)

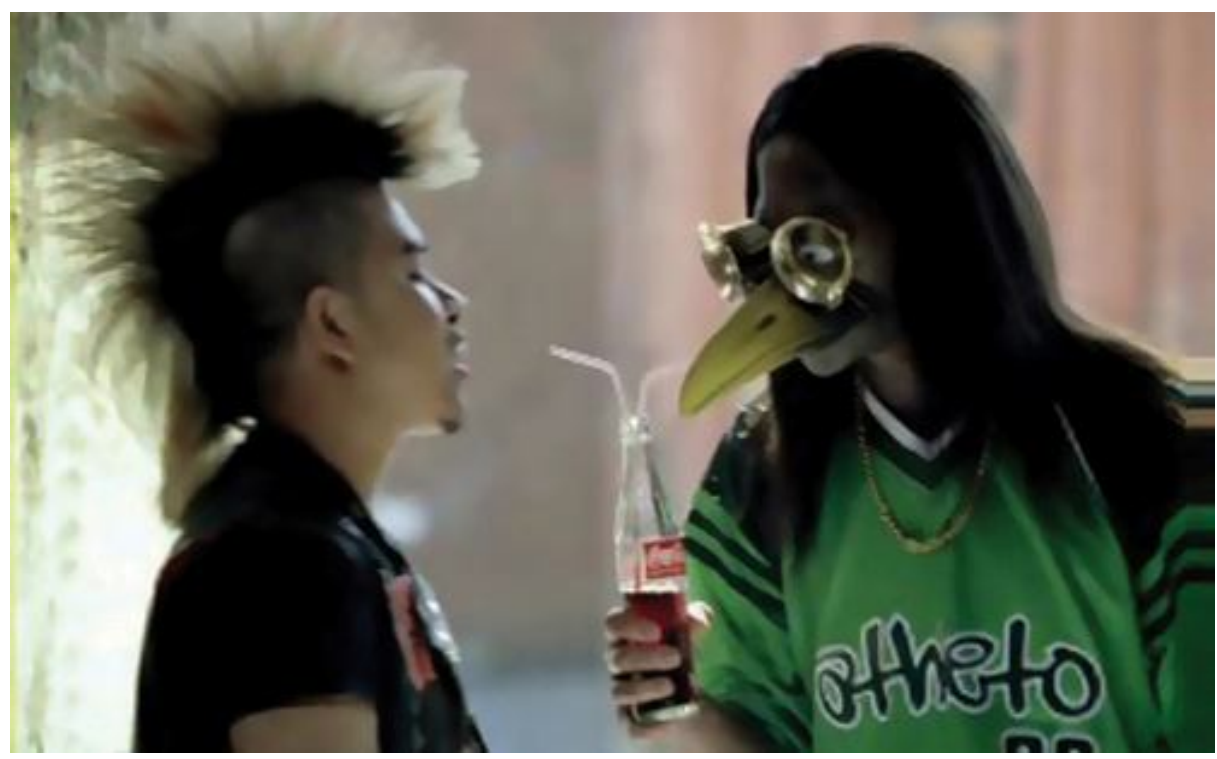

Figura. 03 - Frame do VT Birdman (40 segundo) 


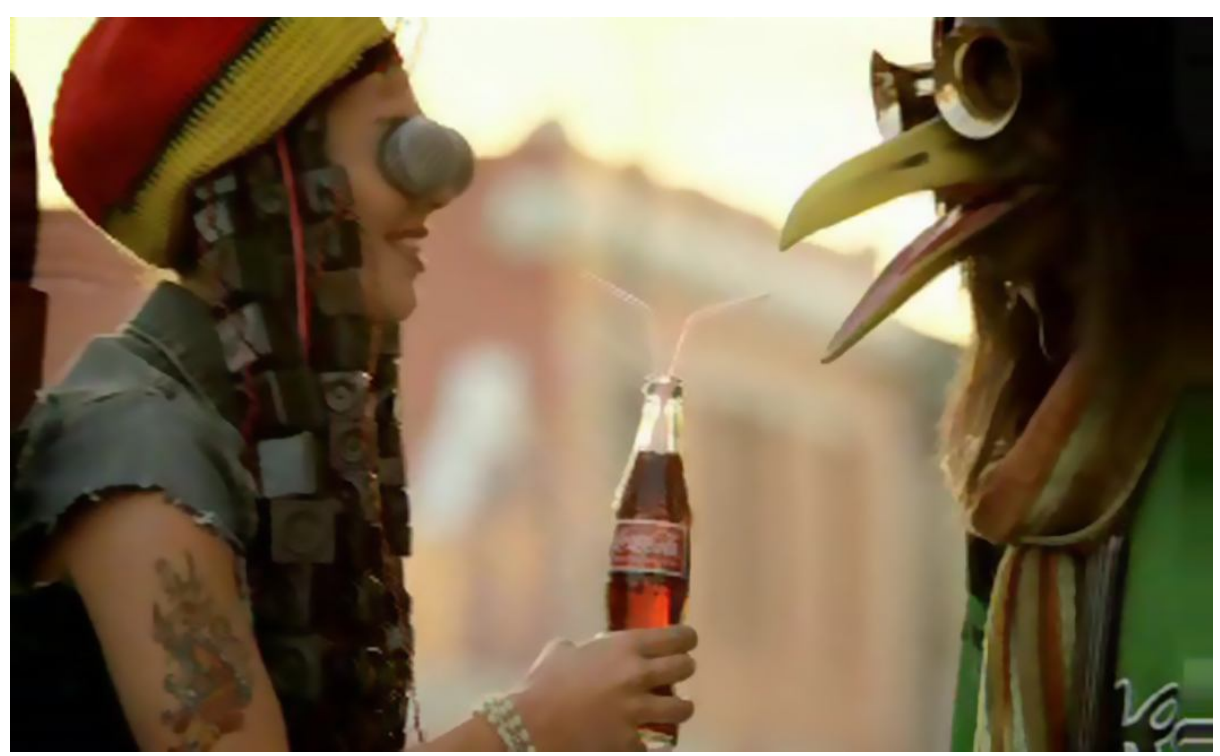

Figura. 04 - Frame do VT Birdman (56 segundo)

Considerando essa complexidade que caracteriza e, de certa forma, configura as questões sobre diferença, como pensar educacionalmente, a alternativa visual mítica apresentada pelas imagens do comercial Birdman de Coca-cola? Marita Sturken e Lisa Cartwright (2001) já haviam feito pergunta semelhante quando se debateram com as polêmicas campanhas da Bennetton. Elas se colocavam as seguintes questões: "Qual, então, é a condição das preocupações sociais e movimentos políticos quando são tão facilmente cooptados em nome do comércio?". E mais: "Uma declaração política tem alguma força quando é parte integral de uma campanha para vender um produto?" Em sintonia com as autoras, nos perguntamos: que "diferença" é essa de que fala o VT da Coca-Cola?

Diversos são os interesses que aparentemente confluem na defesa da pertinência dos discursos sobre "diferença", mas é necessário ressaltar que eles não são idênticos ou congruentes. Em decorrência, é possível encontrar "diferentes esquemas de respostas" para esse problema (ANDRÉ, 2006).

Peter McLaren (2003) destaca que a noção de diferença é um produto da história, da cultura, de embates simbólicos entre grupos que lutam em desigualdade de poder, ou seja, o que está em jogo é justamente o que vem a ser a diferença. Assim, na contemporaneidade, a palavra "diferença" e as imagens que se relacionam a ela são lugares políticos estratégicos.

Tomando o campo da Educação da Cultura Visual como referencial teórico e as interpretações de alunos do Curso de Licenciatura em Artes Visuais da Faculdade de 
Artes Visuais da Universidade Federal de Goiás - FAV/UFG - sobre o VT publicitário Birdman, da Coca-cola, este artigo se propõe a discutir conjunções e disjunções entre celebrações dos diálogos interculturais percebidos como dinâmicas promotoras de aprendizado e, por outro lado, discursos que advogam em favor da gestão de distâncias entre os diferentes - considerações cujo termo "respeito" era a palavra de ordem. Assim, este texto apresenta resultados parciais da análise de entrevistas individuais e em grupo focal realizadas em setembro e novembro de 2009. As entrevistas buscaram explorar e discutir como esses futuros professores se relacionam com a ideia de diferença cultural a partir das imagens do VT publicitário Birdman.

\section{I magem publicitária e a educação da cultura visual}

De antemão é necessário abordar os motivos que nos levaram à escolha de imagens publicitárias. A cultura visual se volta para experiências visuais - ver e ser visto - e não apenas para imagens de um determinado repertório. Conseqüentemente, a cultura visual rechaça distinções entre cultura superior e inferior que privilegiam o estudo de objetos reconhecidos como parte integrante das belas artes. Desse modo, a cultura visual abrese ao estudo e análise de aspectos da vida cotidiana, incluindo aqueles da cultura midiática, anteriormente e, com freqüência, ignorados. Ao discutir a pertinência da substituição da palavra "arte" pela palavra "visual", Martins explica que:

O caráter inclusivo desta dilatação semântica abre espaço para discussão sobre as práticas culturais do ver e suas relações com a subjetividade, reconstruindo o conceito de valor num mundo sitiado por imagens que preenchem e instituem a experiência do cotidiano. (MARTINS, 2007, p. 33)

As imagens midiáticas estão de fato muito mais presentes no cotidiano de jovens e crianças do que aquelas consideradas artísticas pelo cânone de críticos e galerias (JAGODZINSKY, 2005). Assim, segundo a educação da cultura visual é preciso reconhecer o poder que as imagens midiáticas exercem e também a necessidade de nos apropriarmos delas como recurso pedagógico. Como explicita Hernandez:

Trata-se de se aproximar destes "lugares" culturais, onde meninos e meninas, sobretudo os jovens, encontram hoje muitas de suas referências para construir suas experiências de subjetividade. Umas referências que não costumam ser levadas em conta pelos docentes, entre outras razões, porque as consideram pouco relevantes, a partir de um enfoque do ensino centrado em alguns conteúdos disciplinares e em uma visão da escola de cunho objetivista e descontextualizado. (HERNANDEZ, 2007, p. 37)

Assim, por mais que a escola tente ignorar o mundo além de seus muros, grande parte do repertório dos alunos se constrói fora da escola, especialmente por meio das imagens midiáticas. 
Como alerta Santiago Colas (apud STURKEN \& CARTWRIGHT, 2001, p. 239), “nós podemos tentar esquecer ou ignorar a cultura de massa, mas ela não vai nem nos esquecer, nem nos ignorar". Sendo as mídias hoje "o principal veículo de distribuição e disseminação da cultura" e os significados que difunde, uma "forma dominante" de construção de realidade (KELLNER, 2001, p. 54), vê-se que têm, portanto, potencial educativo central para nossa sociedade. As mídias são em grande parte responsáveis pela construção dos sentidos que damos ao mundo, pelos repertórios que usamos para percebermos a nós mesmos, aos outros e o sentido de nossa existência na sociedade e de nossos desejos para o futuro.

Desse modo, toda prática de educação interessada em "contribuir para o aparecimento de 'atores' com capacidade de ação e de resistência" (HERNANDEZ, 2007, p. 17) e em "possibilitar que os leitores e os cidadãos entendam a cultura e a sociedade em que vivem" (KELLNER, 2001, p. 20) deve estar ciente de que a viabilidade desse intento depende de que enfrentemos e compreendamos criticamente as novas condições midiáticas.

A publicidade é parte importante dessa nova condição na medida em que financia o sistema midiático e também sustenta a ideologia consumista necessária à manutenção do sistema capitalista como o conhecemos hoje. Em narrativas imagéticas sobre "a vida como ela deveria ser", ou sobre o que a "vida boa é" (STURKEN \& CARTWRIGHT, 2001, p. 189), a publicidade representa necessariamente os valores de nossa sociedade.

Os anúncios são narrativas sobre nossas vidas, e seu estudo pode apontar discussões bastante importantes para entender representações sociais e a própria ideologia do pensamento burguês. A publicidade deve, portanto, ser estudada como uma narrativa capaz de revelar valores que indicam práticas sociais, fomentam significados que atribuímos às nossas vidas, orientam formas pelas quais nos relacionamos com as coisas e com as outras pessoas. (ROCHA, 2006, p.16)

Práticas questionadoras sobre nossa sociedade não podem omitir-se ao trabalho com este tipo de imagem. Assim, é preciso questionar o rechaço que alguns educadores alimentam diante de produtos midiáticos como a publicidade. Em primeiro lugar, tais produtos não devem ser rejeitados com base no preceito questionável de que se conformariam exclusivamente aos interesses "alienadores" das classes hegemônicas globais, afinal, "seus produtos também participam dos conflitos sociais entre grupos concorrentes e veiculam posições conflitantes, promovendo às vezes forças de resistência e progresso" (KELLNER, 2001, p. 27). Logo, devemos nos dar conta de que:

[...] precisamente a necessidade de vender significa que as produções da indústria cultural devem ser eco da vivência social, atrair grande público e, portanto, oferecer produtos atraentes que 
talvez choquem, transgridam convenções e contenham crítica social ou expressem idéias correntes possivelmente originadas por movimentos sociais progressistas. (KELLNER, 2001, p. 27)

Precisamos reconhecer que os produtos midiáticos, incluindo a publicidade, são produzidos e interpretados no contexto de uma sociedade cada vez mais complexa e, em decorrência, também refletem nossas ambigüidades. Assim, as tensões (culturais e econômicas) que vivenciamos em sociedade também encontram expressão na cultura da mídia de tal forma que a observação de suas entrelinhas pode servir a ricos exercícios críticos. É neste sentido que Ella Shohat e Robert Stam propõem o uso de produtos audiovisuais midiáticos em uma pedagogia multiculturalista que combata "a seletividade de vozes promovidas pela cultura de massa". Estes autores destacam que podemos "identificar e ampliar as vozes reprimidas" dos produtos midiáticos e, então, "recuperar" seus potenciais críticos e utópicos (SHOHAT; STAM, 2006, p. 471).

A possibilidade de interpretações que negociem ou subvertam os sentidos predeterminados pelos produtores midiáticos e que transformem a imagem midiática em objetos de reflexão sobre a vida da cultura contemporânea é mais um argumento para questionar aqueles educadores que se negam a se apropriar dessas imagens.

A multiplicidade de interpretações é ponto fundamental no repertório teórico da cultura visual. Para tanto, privilegia a abordagem construcionista social, segundo a qual todo significado é resultado de uma construção cultural, isto é, social, em detrimento das abordagens miméticas, na qual o significado estaria incrustado nas próprias imagens, e intencional, na qual o significado de uma imagem estaria submisso à intenção do seu autor (HALL, 1997; MARTINS, 2007; STURKEN \& CARTWRIGHT, 2001).

Na abordagem construcionista social, nós apenas interpretamos o significado do mundo material através de específicos contextos culturais. [...] Portanto, o mundo material só tem sentido e só pode ser visto por nós através desses sistemas de representação. Isso significa que o mundo não é simplesmente refletido de volta para nós através dos sistemas de representação, mas somos nós que construímos os sentidos do mundo material através deste sistema. (STURKEN \& CARTWRIGHT, 2001, p. 12-13)

Para compreender os significados das imagens, o campo da cultura visual deixa em segundo plano a imagem em si e a intenção do criador. Segundo Martins, o foco deste campo passa à visualidade, ou seja, o olhar, não enquanto percepção mecânica, mas em sua dimensão cultural (2007, p. 25). "As imagens mudam de significado quando muda o entorno ou o contexto em que são veiculadas" (2007, p. 28). Ou seja, as interpretações 
serão sempre plurais, visto que sempre serão plurais as referências e pressupostos culturais que condicionam a experiência do olhar.

Assim, por si só uma imagem publicitária não tem poder para determinar como ela mesma será recebida. Ela não pode impedir interpretações que subvertam ou ignorem a intenção de seus produtores.

Pensar a experiência do olhar sobre as imagens midiáticas publicitárias como um momento ativo permite-nos mais do que simplesmente a constatação da multiplicidade de interpretações para uma imagem, desloca nossa atenção para o questionamento sobre o porquê de alguns sentidos tornarem-se amplamente compartilhados, tornaremse hegemônicos, e outros não. Pode oportunizar produtivas discussões sobre os repertórios culturais que possibilitam esses olhares, ou, dizendo melhor, sobre o modo como eles são construídos em negociação marcada por desiguais relações de poder entre as mídias, as instituições culturais por excelência da chamada sociedade do consumo e/ou do espetáculo, suas ações globais e as diversas matrizes periféricas que marcam os contextos específicos a partir dos quais se constroem esses olhares. Permite-nos refletir sobre o papel da imagem na vida dessa cultura mundializada e os interesses (democráticos, sociais e éticos) que ainda insistem em resistir à sua sedução.

\section{Birdman e o diálogo intercultural: um aprendizado que advém da diferença}

Birdman, como qualquer outra narrativa visual, promoverá sempre experiências do olhar marcadas por singularidades, a depender de quem o vê e de quando o vê. Durante as dinâmicas das entrevistas individuais e dos grupos focais realizadas com a colaboração de alunos da Licenciatura em Artes Visuais FAV/UFG, foi possível constatar relances desta potência. Relances expressos em declarações encharcadas de histórias de vida. Vislumbrávamos a cada entrevista um novo Birdman especialmente entrelaçado a novas referências, construído em discursos costurados por outras linhas de pensamento que nos fizeram refletir sobre este VT ao mesmo tempo em que se tornava possível conhecer um pouco mais de cada aluno. Em meio a essa diversidade, as interpretações trouxeram tanto pontos que corroboravam uns com os outros, quanto pontos que geravam confrontos, divergências e contradições.

Assim ocorreu com o tema da diferença cultural. Em alguns momentos uma ênfase dada pelos alunos no início da entrevista ia aos poucos cedendo lugar a outros focos à medida que eles ponderavam acerca das questões propostas e de suas próprias opiniões. Por vezes com a verbalização imediata da expressão diferença cultural, por vezes de forma 
incerta quando apenas utilizavam a expressão diferença. Neste último caso foi importante questioná-los se consideravam que o VT poderia ser utilizado para promover discussões sobre o tema "diferença cultural" e, porque, fosse a resposta sim ou não. Por fim, fomos surpreendidos por leituras singulares que nos desafiaram e motivaram a rever nossas interpretações. Desde já, podemos afirmar que as entrevistas contribuíram para discutir uma série de nuanças em jogo na definição deste tema. É sobre estas falas que agora nos debruçamos, destacando inicialmente o valor dado pelos alunos ao aprendizado decorrente do diálogo intercultural. Vale ressaltar que, nesta pesquisa, optamos por identificar os alunos por nomes fictícios, nomes de cores: Lilás, Marinho, Violeta, Oliva, Rosa e Carmim.

Lilás e Violeta foram as colaboradoras que de modo mais flagrante e imediato estabeleceram uma relação entre Birdman e a idéia de diferença cultural. Logo após Lilás ter assistido ao VT, perguntamos se teria alguma consideração a respeito do vídeo. Ela então disse:

Ah! Eu acho ele bem objetivo mesmo (né?). E fala "viva a diferença cultural". E viva a democracia também. Por que, - tipo assim - é quase um cachimbinho da paz (né?). Ele vai lá pro mexicano e bebe um pouquinho. Para um passarinho e bebe um pouquinho. É... com o resto do povo lá e bebe um pouquinho! Aí, ele acaba absorvendo aquilo também. E o interessante é que "viva a diferença cultural", "viva a democracia", por ele ter acesso a tudo isso, absorver a tudo isso porque no final ele está com um pouquinho de cada um (né?). Então, ele foi aberto a aceitar a diferença do outro.

Segundo o viés de sua análise podemos interpretar que o personagem que se movimenta para o encontro com outros promove rituais de contato, de comunicação com indivíduos até então distantes. Entre eles há divergências que provocam a necessidade de utilizar um amuleto (o próprio refrigerante), um objeto mágico, "um cachimbinho da paz", segundo Lilás, que como uma ponte conecta as duas margens antes separadas por conflitos.

Como Lilás, Violeta interpretou igualmente o VT como um momento de diálogo, de troca, de aprendizado. Para ela o que havia de negativo no VT seria exclusivamente o consumo de Coca-cola, no mais o classificava como positivo, pois achou "bacana a questão da relação cultural". Ela disse:

Eu acho que está mostrando um produto que é consumido por diversas pessoas de diversas culturas. ... É... e mostra também a relação (né?). Mostra um lado não racista de culturas. Assim, aquela pessoa que aceita todas as culturas, que troca experiências. Igual no momento dele tomar a Coca-Cola. [...] Então, eu interpretei essa propaganda como uma relação de culturas, troca de culturas. 
Em suas primeiras considerações sobre o VT, Rosa também declarou que o "diálogo" entre as diferenças, "a questão da partilha" e o fato do personagem conseguir "absorver um pouco de cada um" havia Ihe chamado a atenção. Para ela, isso refletia a forma como o processo de aprendizagem se dava no ambiente escolar. "Ele foi se construindo (né?). Por que é mais ou menos isso... Assim... é... é uma construção essa questão da escola. [...] E a gente vai aprendendo um com o outro. Não é sozinho, não!" - argumentou.

Oliva, logo após assistir ao VT, manifestou que percebia a inclusão de várias diferenças: diferença social, de raça, de faixa etária, de espécie e de sexo. Em seguida, ao ser provocada acerca da possibilidade de discutir diferença cultural a partir de tais imagens, também salientou que via "pessoas diferentes, modos de pensar diferente". É importante notar que, durante a fase de entrevistas individuais, ela foi a única colaboradora a expressar nitidamente sua compreensão de cultura como um "modo de pensar".

Oliva em uma situação específica da entrevista descreveu o VT como um momento de viver as diferenças, conhecer as diferenças, "saber lidar com as diferenças". Como Rosa, ela também destacou o aprendizado que decorre da relação com o outro, da relação intercultural. Refletindo sobre sua própria experiência no Brasil, fora de seu país de origem, Cabo Verde, ela concluiu que fatalmente a pessoa se torna mais maleável ao lidar com 'diferentes' e com a sua própria cultura. "Você acaba ganhando quando você está tendo esse contato com outra cultura, você acaba ganhando novos elementos e acaba perdendo outros elementos. Isso eu acho que é inevitável." - ela afirma. Dessa forma, Oliva pontua que nesses diálogos o aprendizado envolve repensar crenças antes naturalizadas. "Eu descobri, eu aprendi coisas. Perdi coisas que eu não ia perder se eu continuasse lá em Cabo Verde. Eu acho que ia ser um processo lento." - confessou. Assim Oliva revela que à medida que se aprende a respeito dos outros, surge a necessidade de conhecer mais sobre si mesmo e a história, a história de seu país, no caso.

Eu acho que, assim... Isso despertou em mim esse contato, conhecer mais sobre a África. Conhecer mais sobre o meu continente. Porque eu conheço mais do continente europeu do que do continente africano. Não é que eu não tenha estudado, estudei história africana, mas um semestre. E a européia? A Européia eu estudei um monte. Então é um eurocentrismo fortíssimo.

Examinando este fato, quando interrogada acerca de como discutiria diferença cultural, ela afirmou que até aquele momento não se sentia segura para trabalhar esta questão em sala de aula, pois primeiro precisava trabalhá-la consigo, para posteriormente discutir com os outros. 
Marinho também ressaltou o contato, o diálogo e o aprendizado com o diferente em sua interpretação, contudo, a idéia de diferença que observou no VT tem contornos próprios e, consequentemente, diverge da percepção dos outros colaboradores. Ao contrário de Lilás, Violeta e Oliva que classificaram as diferenças do VT como diferenças culturais, para Marinho os diferentes foram interpretados como "travestidos". Ele descreveu a narrativa do VT da seguinte forma:

Essa questão de viver as diferenças, que na verdade começa ali com a representação do rapazinho branco (né?), que depois vai passando aquela coisa, o canudo também... Coloca essa coisa do viver mesmo, viver mesmo, que é como se fosse uma passagem de líquido para a língua... Por que na verdade, dois canudos num líquido só, misturam tudo e ao misturar isso... É... Foi quando começou a questão do travesti, a questão dos personagens vestidos, foi quando as galinhas, ali dançando, aquela coisa toda, e o menino ao mesmo tempo ali, ele foi se transformando. É como se essa coisa do viver as diferenças desse outras possibilidades para ele.

O sentido que Marinho dá à idéia de travesti, ele próprio esclarece na citação acima como "a questão dos personagens vestidos", ou seja, personagens fantasiados. Fica apenas subentendida a relação que ele estabelece com o universo gay quando enfatiza "aquela coisa do som" e a "sainha" da personagem como "coisa das paradas [gay]". Ele ainda afirma: "às vezes essa questão que eu falei do travesti pode dar uma outra, um outro significado atrás também... que pode colocar também a questão dos prostíbulos, não sei, ou da homossexualidade". Neste sentido as possibilidades a que se refere como resultado de "viver as diferenças" ganha um contorno próprio.

A relação entre diferença cultural e sexualidade não ficou explicita nos discursos de Marinho, contudo, o tema da homossexualidade foi recorrente nas entrevistas de outros alunos, especialmente quando apontaram os conflitos culturais que percebem em seu dia a dia, na sala de aula ou em outros espaços. Gostaríamos de sublinhar o interesse latente nessa discussão e a força que a disciplinarização da sexualidade ocupa em estruturas culturais e educacionais ao longo da história da humanidade. Não é por acaso, portanto, que os alunos trouxeram este tema à tona.

\section{A gestão da distância: a idéia de respeito sob questionamento}

A partir das interpretações sobre as imagens do VT Birdman foi possível observar que apesar de entenderem as relações de diálogo intercultural como positivas, pelo aprendizado que promovem, alguns alunos sustentam certas ressalvas quanto à 
intensidade das conseqüências desta experiência. Neste artigo nos interessa também discutir certas sugestões acerca da importância da gestão das distâncias entre os diferentes, considerações expressas através de discursos cujo termo "respeito" é a palavra de ordem.

Considerando todas as entrevistas, somente Lilás não julgou como problemático discutir a diferença cultural. Segundo suas palavras, "se você fosse trabalhar a diferença cultural na época de Hitler isso seria um problema. Eu acho que hoje as coisas são mais tranqüilas, mais de boa (né?). Por que é muito engraçado, tem a globalização, então, você sabe que tem essas diferenças".

Semprini (1999) também identifica o trauma do genocídio judeu como o momento em que "o respeito e a valorização da diferença tornaram-se dimensões estruturadoras da cultura política [ocidental], como antídoto contra a eventualidade de um retorno à barbárie" (p.158). Contudo, é necessário manter em perspectiva o fato de que esta tendência não é abraçada por todos e, quando é, nem sempre tem a mesma forma. Independente do valor conferido à diferença isso não significa que não circule a sua volta uma série infindável de embates em toda e qualquer sociedade. Não é a toa que os demais alunos identificaram o tema da diferença como foco/fonte de conflitos sérios, fora e dentro das salas de aula, na faculdade e, especialmente, nas aulas do ensino médio.

Dentre os cinco alunos entrevistados, a defesa do respeito como postura central surgiu nas falas de quatro - Carmim, Rosa, Violeta e Marinho - durante as entrevistas individuais a partir de reflexões acerca dos conflitos que eles identificaram nos temas religião e sexualidade (homossexualidade) ${ }^{5}$.

\section{A idéia de respeito surge nas falas dos alunos}

Para Carmim, a cada dia que passa se torna mais complicado discutir esses tópicos "principalmente no âmbito escolar". Após citar o exemplo que observara na escola em que trabalha - um aluno que por ter trejeitos femininos foi "excluído" e "motivo de riso para os colegas" - Carmim declarou: "São diferenças que eu acho difícil de trabalhar. Por que o professor às vezes... É difícil deixar a questão da religião hoje. Está aí e eu acho difícil. São duas coisas que eu acho".

\footnotetext{
${ }^{5}$ Fazemos questão de sublinhar que estes temas foram suscitados, trazidos à discussão, livremente pelos alunos sem nenhuma provocação direta da nossa parte.
} 
Para os professores, qualquer discussão sobre este tipo de preconceito é conflituosa devido à existência de códigos de conduta e repressão sexual que se fundamentam em uma moral religiosa. Estes códigos reprimem os sentimentos de alunos que assumem sua homo-afetividade. Carmim identifica o peso de uma moral evangélica como a principal fonte de conflitos em sua escola. Ela diz: "Com essa questão da religião dentro, eu acho que hoje está muito difícil a gente trabalhar a diferença por causa dessa religião aí que está dominando, os evangélicos aí..." Em relação à pergunta se os próprios alunos vêem a religião como empecilho para discussões acerca do tema sexualidade ela afirmou que não, acredita que a fonte das dificuldades é a interferência dos pais dos alunos. Em resposta à questão sobre a forma como as diretoras das escolas agem em relação a essas discussões, Carmim explicou que isso depende, primordialmente, do fato da escola ser religiosa ou não.

Marinho, que assume ser homossexual, também expôs durante a entrevista individual os problemas que enfrenta ao lidar com evangélicos. Assim como Carmim, ele identifica as religiões de corrente evangélica como as principais promotoras desses embates. Marinho revelou, inclusive, os problemas e preconceitos de uma colega de classe, no curso de Licenciatura em Artes Visuais, que é evangélica. O principal problema, neste caso, eram as constantes abordagens dessa colega que acreditava estar fazendo um bem, acreditava que poderia salvá-lo. Em outro momento, quando perguntado sobre o motivo do tema da sexualidade não ser abordado nas salas de aula, ele disse:

É uma mistura, viu? Por que igual aqui, uma escola que tem muitos professores, tem professor católico, evangélico, professor de outras entidades, não é? E tem professores... Eu trabalho com muitos professores que são homossexuais também, mas todos têm que ficar calados por que além deles pode ter uma chefe maior que é uma diretora, que é evangélica.

Em decorrência deste receio, segundo Marinho, quando este tema surge na sala de aula, quando um aluno homossexual sofre preconceito, o professor com medo de perder seu emprego "não vai poder levantar uma bandeira para defender este aluno". Fica claro, assim, que quando um grupo é simbolicamente marcado ou estigmatizado, isso fatalmente produz conseqüências, pois, o aluno que é excluído socialmente, terá desvantagens materiais (WOODWARD, 2006, p.14). Analisando este contexto problemático de medo e ofensa, Marinho ressalta que o respeito é muito importante, é fundamental, porque "ninguém vive sob a regra de ninguém. Porque o indivíduo tem de ser mais do que livre para poder ser o que é". I gualmente, Carmim ressaltou a importância de se respeitar o que definiu como a "opção de cada um". 
Rosa também trouxe o tema religião para a discussão ao explicitar a razão porque não se aborda/trabalha o tema diferença cultural em sala de aula. Explicou que o tema diferença cultural é abordado, discutido em sala de aula, mas não com a importância que merece. Deu como exemplo a discussão sobre diferença cultural propiciada pela novela "Caminho das índias", discussão que provocou "um reboliço".

Nossa! Foi um rebuliço. Eu ouvi cada relato. "Nossa! Esse trem é do demônio. A música é do demônio. Olhem lá, vocês tem de ver a letra, vão à internet." [...] É a música da abertura. Enviaram um monte de e-mail pra mim falando: "Olha a letra! Isso é coisa do capeta".

Após este depoimento, nos sentimos instigados a perguntar se ela se sentiria a vontade, enquanto professora, para trabalhar com os alunos o exemplo que acabara de dar. Ela então respondeu:

Se eu levasse... É porque (aí) entra toda essa questão da religião. Dessa questão de que não é permitido, de que é pecado. Aí, teve aquela música do Caetano "é proibido proibir" (né?). Mas, assim... Tinha de conversar com eles mais tranquilos. Por que é o que eles acham. [...] Mas é complicado, por que quando fala que é do demônio todo mundo tem medo. Tudo quanto é culpa que tem do mal é do demônio. Acho que ele está até cansado, o capeta (sorrisos). Nossa! Tudo de mal é ele.

Embora considerando o tema religião como algo delicado, difícil de abordar nas escolas de Goiânia, Rosa afirmou que não o desconsideraria. Comentamos sobre a obrigatoriedade do tema "cultura africana" 6 na educação básica e questionamos como ela compreendia a possibilidade de trabalhar com alguma imagem/fotografia ${ }^{7}$ de rituais do candomblé. Após um momento de pausa e reflexão, ela afirmou que trabalharia com o tema, mas que daria "pano pra manga", ainda mais por ser "candomblé, terreiro", uma religião que é vista com temor por muitas pessoas com as quais convive. Segundo Rosa, este temor também seria um problema caso a religião fosse espírita. Ela disse: “Igual espírita (né?) O pessoal morre de medo... pelo menos com os que eu convivo... falam: ‘Não! Povo espírita, não. Isso não é de Deus, não! Nossa! Negócio de reencarnação!”.

É importante destacar que alguns autores apontam para um aumento significativo da discriminação e da exclusão provocadas por conflitos como estes entre diferenças culturais ligadas a crenças religiosas. Esta observação vem provocando críticas a um tipo de multiculturalismo focalizado exclusivamente sobre o racismo biológico que

${ }^{6}$ A Lei 10.639/2003 institui a obrigatoriedade do ensino de História e Cultura Afro-brasileira e Africana na Educação Básica.

${ }^{7}$ Nossa escolha por este tipo de imagem se deu em decorrência da aluna ter relevado anteriormente um interesse por trabalhar com imagens fotográficas. 
absurdamente ignora os choques culturais religiosos (HALL, 2006). Em decorrência desta omissão à questão religiosa, surge a suspeita de que existe um tabu nesse questionamento, como se o princípio constitucional da liberdade de crença justificasse uma aceitação imediata e inquestionável.

Como sugere o depoimento de Rosa, discutir religião envolve um tipo de receio. Neste sentido, pensando sobre a forma de trabalhar o tema diferença cultural entre religiões, Rosa entende o respeito como uma postura fundamental. Ela expôs o seguinte argumento: "Eu não vou mudar a cabeça do aluno. Eu tenho que respeitar. Se ele acha que é... Eu poderia até conversar com ele, tentar argumentar, mas... se mudasse..." disse com um ar de incredulidade.

O tema 'respeito' surge no relato de Violeta com o mesmo tom de descrença em relação

à possibilidade de promover maior compreensão sobre as diferenças culturais. Embora não faça relações com religiosidade, assim como fizeram Marinho e Carmim, Violeta também menciona o tema preconceito contra alunos homossexuais quando questionada em relação as suas percepções sobre o tema diferença cultural. Ela salientou que é difícil trabalhar este tema em sala de aula porque "numa turma que tem cinqüenta alunos e um é homossexual, só um vai entender do homossexualismo" e, por isso, considera que a "questão do respeito" é, talvez, a maneira mais adequada para abordar a questão.

Vale ressaltar que, ao refletirem sobre os exemplos de conflitos culturais descritos acima, nas entrevistas individuais os alunos já haviam se posicionado sobre o respeito como postura básica, necessária. Como revela Silva (2006), hoje, a posição pedagógica recomendada é a postura do respeito. Entretanto, o autor questiona-se: “Mas será que as questões da identidade e da diferença se esgotam nessa posição liberal? E, sobretudo: essa perspectiva é suficiente para servir de base para uma pedagogia crítica e questionadora?" (2006, p. 73). Buscando compreender melhor como os alunos consideram que o respeito pode promover aprendizagem, tentamos aprofundar esta discussão nos grupos focais. Nossa intenção era averiguar como os alunos se posicionam em relação à contradição entre esta abordagem e a do diálogo intercultural por eles advogada durante a interpretação do VT Birdman.

\section{Questionando a noção de respeito e seu valor pedagógico}

Para nossa surpresa, o tema acabou surgindo durante a primeira entrevista focal antes do momento programado para a discussão, a partir do questionamento sobre os motivos que justificariam a importância da diferença cultural. Em decorrência deste fato, 
pudemos perceber que para os alunos estas questões eram fundamentalmente a mesma. Por esta razão faremos esta discussão em um único bloco.

Historicamente, os seres humanos têm revelado que a diferença pode ser entendida de formas opostas, tanto por um viés negativo, quando a ignoramos, marginalizamos ou até mesmo tentamos expurgá-la, quanto por um viés positivo, quando a celebramos como fonte de diversidade, hibridismo e enriquecimento. Embora sejam muitas as respostas, de forma alguma elas são obvias. Daí a importância das questões propostas por Semprini (1999, p.11): “Como se pode tratar da diferença? Qual é seu lugar dentro de um sistema social? A diferença é um fato de enriquecimento ou, ao contrário, empobrecimento? Um trunfo ou uma ameaça?" Durante as dinâmicas dos grupos focais, embora já estivéssemos cientes de que os alunos conferem valor positivo à diferença cultural, nos interessava ter mais clareza sobre as suas justificas para essa valorização. Questionada, Lilás respondeu de maneira rápida e simples: "Para demonstrar a individualidade de cada um!". Com a mesma prontidão, Violeta afirmou: "Para se obter respeito!". Em seguida, ela explicou seu posicionamento utilizando o exemplo da religião:

Eu acho que o tema religião é um tema difícil de ser trabalhado. Mas dentro da religião, como cada pessoa tem a sua, a gente tem de trabalhar dentro da religião o respeito e o respeito pelo próximo por ele optar por aquela religião. Acho que a gente pode discutir sim, para o aluno conhecer $\{$ né?\} e utilizar bem a questão do respeito.

Quais os valores em jogo nessas respostas? Na parte anterior deste texto, dialogamos com vários autores que apontam para as praticas de mestiçagem, hibridização ou tradução cultural como possibilidade de nos tornarmos menos fundamentalistas, mais flexíveis, num mundo em que aprender a se adaptar a mudanças constantes é imperativo. É sobre isso que falam Lilás e Violeta? Vejamos, então, o posicionamento de Marinho e Rosa.

Quando perguntado sobre a importância das diferenças, Marinho disse: “É porque todo mundo é diferente! É uma coisa tão boba para responder, \{né\}?" Percebe-se que, para este aluno, a diferença não é uma escolha, ela fatalmente ocorre. Quanto ao respeito, Marinho explicou sua importância com as seguintes palavras: “Por que o respeito...é,... ele limita o seu espaço, pra você saber até onde você pode ir e não fazer com que você ultrapasse o espaço do outro e vice-versa." De modo bastante semelhante, Rosa explicita que o respeito serve "para não chegar a ofender o outro", para "você ter cautela em relação a isso, para você respeitar o modo de vida do outro, o que ele quer para a vida dele, sei lá". 
Ainda durante as entrevistas individuais, tanto Rosa quanto Violeta definiram a "questão do respeito" como uma possibilidade, uma maneira de trabalhar o tema, visto que ambas viam com incredulidade a possibilidade de alunos preconceituosos mudarem seu modo de pensar, ou seja, tentarem entender o 'outro'. Assim, pode-se observar que o valor em questão não é, primordialmente, o aprendizado a partir do contato com a diversidade, mas, principalmente, a liberdade individual. Por esta razão, Lilás e Violeta justificam sua posição sobre a importância da diferença enfatizando como uma maneira "para demonstrar a individualidade" e "para se obter respeito".

De modo geral, para os alunos, é o outro quem decide o que quer para sua vida e o que ele decide em grande medida não convém a mais ninguém. Para eles, esta liberdade é fundamental. Marinho deixou isso claro na entrevista individual: "o indivíduo tem de ser mais do que livre para poder ser o que é." Há aqui uma clara influência da distinção liberal entre espaço público e privado, segundo a qual questões privadas não estariam abertas à discussão. Em princípio, esta visão individualista mantém as pessoas separadas e, em conseqüência, elas temem a proximidade do 'outro' como um risco ou ameaça. Por isso, Rosa usa a expressão "cautela".

Fazemos algumas ressalvas em relação a essa herança liberal latente na postura dos alunos sobre o tema respeito. Referimo-nos à suposição de um indivíduo livre, portador de soberania sobre si, de racionalidade e autoconsciência. Conceituado dessa forma, o indivíduo renega o fato de que somos formados a partir de nossas inter-relações sociais, somos sujeitos coletivos, pois estamos sujeitados à coletividade. Como explica Semprini (1999, p.102):

\begin{abstract}
A percepção que um indivíduo tem de si mesmo e de sua individualidade depende de estruturas cognitivas, esquemas corporais, afinidades comuns e outras qualificações inscritas num quadro que emerge somente no decurso de interações com os membros de seu grupo de pertença e dos outros grupos sociais. Em outros termos, a própria capacidade de um indivíduo de se pensar como indivíduo e definir as qualificações desta individualidade é amplamente determinada por suas interações e experiências sociais.
\end{abstract}

Assim, parece claro que as escolhas dos sujeitos, longe de serem simples registros de liberdade, estão intrinsecamente ligadas às estruturas de poder que marcam o contexto cultural da sociedade na qual se inserem. Neste sentido Hall (2006, p.77) afirma que "a vida individual significativa está sempre incrustrada em contextos culturais e é somente dentro destes que suas 'escolhas livres' faz sentido". 
Em decorrência destas reflexões, surge, então, a necessidade de questionarmos a concepção liberal que se fundamenta no princípio de "neutralidade" do Estado como garantia da autonomia pessoal e a liberdade do indivíduo para buscar sua própria concepção do "bem", desde que isso seja feito no domínio privado. Ocorre que, tanto a neutralidade de uma esfera pública quanto a sua separação de uma esfera privada, tornam-se, então, inconcebíveis.

O liberalismo hoje não é 'a cultura além das culturas', mas a cultura que prevaleceu: aquele particularismo que se universalizou com êxito e se tornou hegemônico em todo o globo. Seu triunfo ao praticamente estabelecer os limites do domínio "da política" não foi, em retrospecto, o resultado de uma desinteressada conversão em massa à Regra da Razão Universal, mas algo mais próximo a um tipo de 'jogo' de poder-conhecimento mais mundano e foucaultiano. (HALL, 2006, p. 73)

Desse modo, é possível observar uma operação para encobrir nossas relações de poder desiguais tanto ao que convém à neutralidade do espaço público, quanto à sua separação do espaço privado e à liberdade dos indivíduos. Silva (2006) defende que o foco seja dirigido justamente para estas relações de poder até agora ocultadas pela pedagogia do respeito e/ou tolerância. Embora identifique que os temas identidade e diferença estão sendo reconhecidos como legítimas questões de conhecimento pelos currículos oficiais, o autor chama atenção para o fato de que, soterrada por uma simplória admissão da existência da diversidade, uma teoria da identidade e da diferença fez-se ausente. Para o autor, falta explicar como identidade e diferença são ativamente produzidas.

A identidade, tal como a diferença, é uma relação social. Isso significa que sua definição - discursiva e linguística - está sujeita a vetores de força, a relações de poder. Elas não são simplesmente definidas; elas são impostas. Elas não convivem harmoniosamente, lado a lado, em campo sem hierarquias; elas são disputadas. (SILVA, 2006, p. 80)

Em decorrência desta tomada de consciência, Silva sugere que aproveitemo-nos das contribuições da teoria cultural recente, em especial aquela com herança pósestruturalista, para que possamos tratar identidade e diferença "como processos de produção social, como processos que envolvem relações de poder" (p.96), "como questões de política" (p.99).

Dos alunos colaboradores, apenas Oliva fez críticas à postura do respeito. Ela disse:

[...] falando sobre respeito, às vezes a gente fala " $\{$ Não $\}$ ", por exemplo, "eu não gosto de negro, mas eu respeito. Eu não gosto 
de gay, mas eu respeito", entendeu? (...) Eu acho que... Eu acho que tem que ser mais uma questão de aceitação, porque respeito é... Desse jeito: "eu não tenho nada..." Muita gente, em relação... - Isso acontece muito com a homossexualidade. [Marinho Acontece, muito.] Com a homossexualidade. "Não, eu não tenho nada contra. Desde que ele não chegue perto de mim". [Marinho (sorri) Han ram...]

Para Oliva, o respeito seria em grande medida uma gestão da distância entre aqueles que não tem interesse no contato com o 'outro'. Sua análise revela questões que não costumam ser friamente encaradas. É possível identificar, tomando sua posição como referência, uma carga de hipocrisia nos discursos sobre respeito. Oliva é explicita: "Não, eu não tenho nada contra. Desde que ele não chegue perto de mim". Considerando a impossibilidade de negociação, devido à inexistência de interesse no contato, pois como ela reafirma, de fato "eu não gosto" do outro, a única saída seria uma distância que nos separe, ou, possivelmente, a distância que fundamenta a separação entre esfera pública e privada.

De acordo com Shohat e Stam (2006, p. 474), "a noção de relativização mútua e recíproca, a idéia de que as diversas culturas deveriam perceber as limitações de suas próprias perspectivas sociais e culturais" deve ser central para toda pedagogia multicultural. A questão que se faz premente é: nestes moldes liberais o respeito de alguma forma se ampara nesta consciência de relativização mútua? Assim, fica evidente que, para os indivíduos, o que pauta a postura de respeito é a ideologia da liberdade individual, a liberdade que o outro tem para escolher o que quiser para sua vida, “inclusive os repertórios, para mim, mais execrável, desde que a distância entre nós seja tamanha que possamos viver sem nenhum contato". O risco que este tipo de pedagogia apresenta é: ao mesmo tempo em que a liberdade e a separação são tratadas como passo para respeitar as culturas, essa relação "acaba paralisando-as e isolando-as umas das outras, desconsiderando seus movimentos e dinâmicas, resultante, muitas vezes do contato entre elas" (TEIXEIRA; LOPES, 2006, p.15)

Para Oliva, mais do que "respeito" ou "tolerância", o importante é a vivência. "Respeitar é deixar distante. É vivenciar. Você tem que vivenciar a experiência." - conclui. Enquanto gerenciamento da distância, se o respeito tem algum valor positivo para a diminuição dos conflitos, em contraposição Oliva alerta para outro problema, o risco de promover uma distância a ponto de impossibilitar o questionamento sobre a diferença. Para ela, "vivenciar a experiência" do contato pode ser a melhor forma de promover essa aprendizagem. Neste sentido, utilizando-se estrategicamente da linguagem liberal, Semprini afirma que "a experiência da diferença coloca à disposição do indivíduo uma variedade de opções significativas para que ele possa diante delas fazer uma livre 
escolha" (1999, p. 104). Assim, quanto maior nossa compreensão sobre o modo como esses repertórios culturais mediam nossas percepções do mundo - como obra humana, como construções sociais sujeitas a relações desiguais de força e não simplesmente revelações ou essências inocentes - maiores nossas possibilidades de nos tornarmos mais flexíveis e menos reféns desses fundamentalismos. Como apresentamos no início desta discussão, o depoimento de Oliva, ao declarar que sua experiência de vida no Brasil a estava tornando "mais maleável" para lidar com a diferença, corrobora de maneira significativa com os argumentos desta análise.

\section{Conclusão}

Na discussão sobre as imagens do VT publicitário Birdman, identificamos com os alunos que colaboraram com a pesquisa uma série de temas polêmicos que cercam a questão da diferença cultural. O valor do diálogo intercultural em contraposição à postura do respeito e da distância entre as diferenças, posição pedagógica mais difundida, são alguns desses temas. Ao final deste texto, assumimos a necessidade de um maior aprofundamento na análise do valor pedagógico do respeito. Concluímos que é necessário colocá-lo em dúvida, não aceitá-lo de saída, inocentemente, sem algumas ressalvas, caso almejemos realmente aprofundar a discussão acerca das relações de poder envolvidas na produção social da identidade, da diferença e do valor do diálogo intercultural. Afinal, devemos nos perguntar: de que serve aos alunos a política liberal do respeito? Se a postura do respeito tem valores, do que abdicamos quando nos limitamos a ela? Uma postura que se sustenta simplesmente na liberdade individual pode prejudicar o diálogo, a negociação e assim a compreensão entre os grupos? Tais perguntas são importantes e merecem que continuemos discutindo-as.

\section{Referências}

ANDRÉ, João Maria. Identidade(s), multiculturalismo e globalização. 2006. Trabalho apresentado XX Encontro de Filosofia: A Filosofia na Era da Globalização, Coimbra, 2006. Disponível em: http://www.apfilosofia.org/documentos/. Acesso em: 3 de dez. 2006.

APPADURAI, Arjun. Modernity at Large: cultural dimensions of globalization. Minnesota: University of Minnesota Press, 1996.

COCACOLABRASIL.COM.BR. Estréia da campanha "viva o lado coca-cola da música" dá início às ações da marca para 2007. Disponível em: http: // www.cocacolabrasil.com. br/release_detalhe. asp? release $=70 \&$ Categoria $=38$. Acess o em: 29 de nov. 2009.

FEATHERSTONE, Mike. O desmanche da cultura: globalização, pós-modernismo e identidade. São Paulo: Studio Nobel/SESC, 1997. 
HALL, Stuart. A questão multiculturalista. In: Da Diáspora: identidades e mediações culturais. Belo Horizonte: UFMG, 2006. p. 49-94.

. The Work of Representation, In: Hall, S. (Org) Representation: cultural representation and signifying practices. London: Sage, 1997.

HERNÁNDEZ, Fernando. Catadores da cultura visual: proposta para uma nova narrativa educacional. Porto Alegre: Mediação, 2007

JAGODZINSKI, jan. As negociações da diferença: arte educação como desfiliação na era pós-moderna. IN: BARBOSA, Ana Mae; Guinsburg, J. (Orgs.). O Pós-Modernismo. São Paulo: Perspectiva, 2005.

KELLNER, Douglas. A cultura da mídia. Bauru, SP: EDUSC, 2001.

MARTINS, Raimundo. A cultura visual e a construção social da arte, da imagem e das práticas do ver. In: OLIVEIRA de OLIVEIRA, Marilda (Org.). Arte, Educação e Cultura. Santa Maria: Editora UFSM, 2007, p.19-40.

MCLAREN, Peter. Multiculturalismo crítico. São Paulo: Cortez: Instituto Paulo Freire, 2003.

ROCHA, E.P.G. Representações do consumo: estudos sobre a narrativa publicitária. Rio de Janeiro: Ed. PUC-Rio: Mauad, 2006.

SEMPRINI, Andréa. Multiculturalismo. Bauru, SP: EDUSC, 1999.

SILVA, Tomaz Tadeu da. A produção social da identidade e da diferença. In: SILVA, Tomaz Tadeu da. (Org.). I dentidade e diferença: a perspectiva dos Estudos Culturais. 6. Ed. Petropólis: Vozes, 2006, p.7-72

STURKEN, Marita; CARTWRIGHT, Lisa. Practices of looking: an introduction to visual culture. New York: Orford University Press, 2001.

SHOHAT, Ella; STAM, Robert. Crítica da imagem eurocêntrica: Multiculturalismo e Representação. Rio de Janeiro: Cosac \& Naify, 2006.

TEIXEIRA, Inês Assunção de Castro. Apresentação. TEIXEIRA, Inês Assunção de Castro; LOPES, José de Sousa Miguel (Orgs.). A diversidade cultural vai ao cinema. Belo Horizonte: Autêntica, 2006.

WOODWARD, Kathryn. Identidade e diferença: uma introdução teórica e conceitual. In: SILVA, Tomaz Tadeu da. (Org.). I dentidade e diferença: a perspectiva dos Estudos Culturais. 6. Ed. Petropólis: Vozes, 2006. p. 73-102. 